
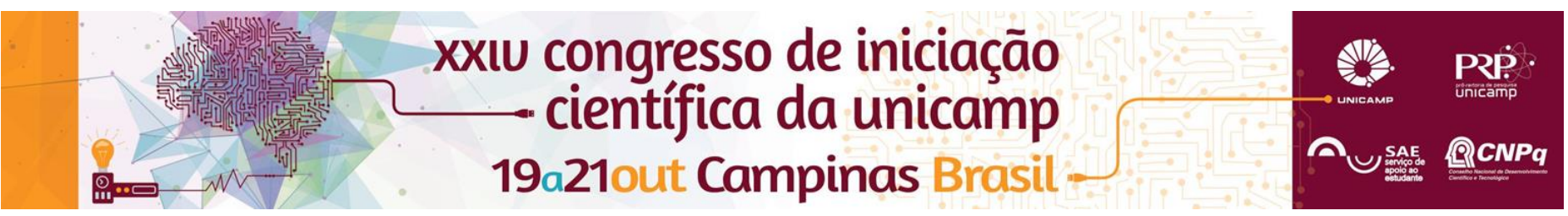

\title{
Título (Principal): Proposição de indicadores para descrição do jogo de futebol de mesa, modalidade Dadinho
}

\author{
Mario Augusto Bernardino Burato (Bolsista SAE/Unicamp)
}

Luciano Allegretti Mercadante (Orientador)

\begin{abstract}
Resumo
A proposição de indicadores para descrição do jogo de futebol de mesa, modalidade Dadinho, são realizadas para definição e descrição dos fundamentos do jogo, através de indicadores em função do tempo de jogo. O objetivo principal deste trabalho é a Proposição de indicadores para descrição do jogo de futebol de mesa, em função do tempo, de 9 partidas oficias do VIII Campeonato Brasileiro Interclubes de FutMesa. As variáveis de jogo analisadas foram: Passe (Certos/Errados), Finalização (Certos/Errados), está subdividida em Finalização Fora, Finalização Gol, Finalização Trave, Inicio Ataque, Fim Ataque, Gol, Fim Jogo, Toque (Certos/Errados), Falta técnica, Intervalo, Inicio Jogo, registrados em função do tempo do relógio do jogo, utilizando o módulo Skout do Sistema DVideo.
\end{abstract}

Palavras-chave: Futebol de Mesa, Dadinho, Fundamentos do Jogo.

\section{Introdução}

O futebol de mesa (chamado antigamente de "futebol de botão") existe há quase um século, com indícios da origem do jogo no Brasil; Segundo as regras oficiais do Dadinho, (FEFUMERJ, 2015), cada unidade do jogo pode ser definida como ataque, dada pela posse de bola de uma das equipes. Em cada ataque de uma equipe, cada botão poderá dar no máximo 3 toques consecutivos, individualmente, e cada equipe poderá dar no máximo 9 toques consecutivos, devendo até o $9^{\circ}$ toque obrigatoriamente dar um chute ao gol. Dessa forma, o jogo pode ser visto como uma sucessão de ataques alternados das duas equipes, onde em cada ataque são realizadas ações que podem ser quantificadas caracterizando o jogo, por análise notacional, ou seja, observação direta de avaliadores (HUGHES; BARLLET, 2002).

Segundo Hughes e Barllett (2002), para descrever e compreender a dinâmica de jogos desportivos, pesquisadores tem utilizado indicadores técnicos de desempenho, que são uma combinação de variáveis de jogo capazes de discernir a eficiência das equipes. Podem incluir fundamentos e outras ações características da modalidade. Assim, a opção deste trabalho foi construir uma metodologia para descrição do jogo, que defina os indicadores técnicos do jogo de futebol de mesa, que podem ser fundamentos e/ou ações realizadas, de maneira seja possível comparar eficiências, caracterizar jogos e oferecer ferramentas precisas para a compreensão da dinâmica do jogo de futebol de mesa na modalidade Dadinho. A proposta aqui descrita foi aplicada em 9 partidas oficiais do VIII Campeonato Brasileiro Interclubes de Futmesa.

\section{Resultados e Discussão}

Notou-se através das tabelas com todos dados estatisticos sobre as médias dos fundamentos das nove partidas analisadas, que o time vencedor troca mais passes, finaliza mais em direção ao gol e utiliza-se mais toques que o adversário, consequentemente, time perdedores.
Média dos fundamentos das nove partidas:

\begin{tabular}{|l|l|l|}
\hline Time Vitorioso/Perdedor & & \\
\hline Média & Certa & Errado \\
\hline Passe & $32.5 / 28$ & $10 / 12.5$ \\
\hline Finalização & $2.5 / 1$ & $10 / 12.5$ \\
\hline Fin. Goleiro & $6 / 3$ & \\
\hline Fin. Fora & $3 / 7$ & \\
\hline Fin. Trave & $1.5 / 2$ & \\
\hline Inicio Ataque & $10 / 9$ & \\
\hline Final Ataque & $9 / 8$ & \\
\hline Gol & $4.7 / 2$ & \\
\hline Fim Jogo & $0,7 / 0,3$ & \\
\hline Toque & $34 / 30$ & $3.5 / 3.5$ \\
\hline Falta Técnica & $3 / 2.5$ & \\
\hline Intervalo & $0,6 / 0,4$ & \\
\hline Inicio Jogo & $0,5 / 0,5$ & \\
\hline
\end{tabular}

Sendo esses dados obtivos através de analises computacionais utilizando-se do programa DVideo, fazendo skout de todos dados, através dos fundamentos básicos descritos nas regras, concluindo que passe, finalização no gol e toque, são os fundamentos, cujo, quando realizados corretamente, são fundamentais para a vitória nesta modalidade.

\section{Referencias}

BLANCO, A.; IBÁÑEZ, S.J.; ANTUNEZ, A.; HERNANDEZ-MENDO, A Estudo da fidelidade dos indicadores de rendimento na Liga ASOBAL. Cuadernos de Psicologia del Deporte, vol. 15, 1, 255-264, 2015.

FIGUEROA, P.J.; LEITE, N.J.; BARROS, R.M.L. Tracking soccer players aiming their kinematical motion analysis. Computer Vision and Image Understanding, 101 (2), 122-135, 2006.

FEDERAÇÃO DE FUTEBOL DE MESA DO ESTADO DO RIO DE JANEIRO.

Regra Dadinho 9x3. Disponível em:

http://www.fefumerj.com.br/documentos/dadinho-documentos/. Acesso em: 20 de agosto de 2015.

HUGHES, M.; BARLLET, R.M. The use of performance indicators in performance analysis. Journal of Sports Science, 20(10), 739-754, 2002

${ }^{1}$ Curtis, M. D.; Shiu, K.; Butler, W. M. e Huffmann, J. C. J. Am. Chem. Soc. 1986, 108, 3335. 